University of Nebraska - Lincoln

DigitalCommons@University of Nebraska - Lincoln

Nebraska Cooperative Fish \& Wildlife Research Nebraska Cooperative Fish \& Wildlife Research Unit -- Staff Publications

2018

\title{
Effects of large-scale wetland loss on network connectivity of the Rainwater Basin, Nebraska
}

\author{
Bram H. F. Verheijen \\ Kansas Cooperative Fish and Wildlife Research Unit, bramverheijen@gmail.com \\ Dana M. Varner \\ Rainwater Basin Joint Venture, Grand Island, NE \\ David A. Haukos \\ U.S. Geological Survey
}

Follow this and additional works at: https://digitalcommons.unl.edu/ncfwrustaff

Part of the Aquaculture and Fisheries Commons, Environmental Indicators and Impact Assessment Commons, Environmental Monitoring Commons, Natural Resource Economics Commons, Natural Resources and Conservation Commons, and the Water Resource Management Commons

Verheijen, Bram H. F.; Varner, Dana M.; and Haukos, David A., "Effects of large-scale wetland loss on network connectivity of the Rainwater Basin, Nebraska" (2018). Nebraska Cooperative Fish \& Wildlife Research Unit -- Staff Publications. 263.

https://digitalcommons.unl.edu/ncfwrustaff/263

This Article is brought to you for free and open access by the Nebraska Cooperative Fish \& Wildlife Research Unit at DigitalCommons@University of Nebraska - Lincoln. It has been accepted for inclusion in Nebraska Cooperative Fish \& Wildlife Research Unit -- Staff Publications by an authorized administrator of DigitalCommons@University of Nebraska - Lincoln. 


\title{
Effects of large-scale wetland loss on network connectivity of the Rainwater Basin, Nebraska
}

\author{
Bram H. F. Verheijen • Dana M. Varner • David A. Haukos
}

Received: 17 April 2018/Accepted: 1 October 2018/Published online: 4 October 2018

(C) Springer Nature B.V. 2018

This document is a U.S. government work and is not subject to copyright in the United States.

\begin{abstract}
Context The Rainwater Basin region in south-central Nebraska supports a complex network of spatiallyisolated wetlands that harbor diverse floral and faunal communities. Since European settlement, many wetlands have been lost from the network, which has increased distances among remaining wetlands. As a result, populations of wildlife species with limited dispersal capabilities may have become isolated and face greater local extinction risks.

Objectives We compared the pre-European settlement and current extent of the Rainwater Basin network to assess the effects of wetland losses on network connectivity for a range of maximum dispersal distances.

Methods We constructed network models for a range of maximum dispersal distances and calculated network metrics to assess changes in network
\end{abstract}

B. H. F. Verheijen $(\bowtie)$

Kansas Cooperative Fish and Wildlife Research Unit, Kansas State University, Manhattan, KS 66506, USA e-mail: bramverheijen@gmail.com

D. M. Varner

Rainwater Basin Joint Venture, Grand Island, NE 68803, USA

\section{A. Haukos}

U.S. Geological Survey, Kansas Cooperative Fish and Wildlife Research Unit, Kansas State University,

Manhattan, KS 66506, USA connectivity and the relative importance of individual wetlands in regulating flow.

Results Since European settlement, the number of wetlands in the Rainwater Basin has decreased by $>90 \%$. The average distance to the nearest neighboring wetland has increased by $150 \%$ to $\sim 1.2 \mathrm{~km}$, and the dispersal distance necessary to travel throughout the whole network has increased from 3.5 to $10.0 \mathrm{~km}$. Last, relative importance of individual wetlands depended on the maximum dispersal distance. Which wetlands to preserve to maintain connectivity might therefore depend on the dispersal capabilities of the species or taxa of interest. Conclusions To preserve a broad range of biodiversity, conservation efforts should focus on preserving dense clusters of wetlands at fine spatial scales to maintain current levels of network connectivity, and restoring connections between clusters to facilitate long-range dispersal of species with limited dispersal capabilities.

Keywords Connectivity · Dispersal distance · Habitat fragmentation · Network modeling · Playa wetlands · Rainwater Basin

\section{Introduction}

The central and southern Great Plains region of North America stretches from Nebraska to Texas and New 
Mexico, USA, and includes a high-density network of $>50,000$ spatially-isolated playa wetlands (Smith 2003). Playas within the Great Plains are shallow, often circular depressions with a hydric clay soil bottom that collect and hold precipitation and runoff water, but are not directly connected to groundwater (Osterkamp and Wood 1987; Smith 2003; Smith et al. 2012). The predominate hydrological state of playas is dry with ponding typically occurring only after a series of intense precipitation events; which wetlands in the network contain water at any time is therefore strongly dependent on the temporal and spatial patterns in precipitation (Haukos and Smith 1993; Smith 2003; Johnson et al. 2011). Depressions may or may not contain water in a certain year, rarely remain flooded continuously among years or potentially remain dry for decades depending on location and precipitation patterns across the region (Johnson et al. 2011). As a result, which wetlands are ponded is highly variable from year to year.

Playas within the Great Plains perform many important ecosystem functions, including aquifer recharge, native plant refugia, floodwater collection, and maintaining local biodiversity (Haukos and Smith 1994; Smith 2003; Smith et al. 2011, 2012). Furthermore, playas provide critical breeding, stop-over, and wintering habitats for many species of invertebrates, amphibians, mammals, and birds, including several species of crustaceans, dragonflies, and snails, eastern narrow-mouthed toad (Gastrophryne carolinensis), Great Plains toad (Anaxyrus cognatus), tiger salamander (Ambystoma tigrinum), western chorus frog (Pseudacris triseriata), harvest mouse (Micromys minutus), northern grasshopper mouse (Onychomys leucogaster), striped skunk (Mephitis mephitis), American avocet (Recurvirostra americana), blacknecked stilt (Himantopus mexicanus), northern bobwhite (Colinus virginianus), and red-winged blackbird (Agelaius phoeniceus; Haukos and Smith 1994; Smith 2003; Smith et al. 2012). Many resident wildlife populations are restricted to ponded wetlands, but individuals can disperse among wetlands to connect local populations and form geographically distinct metapopulations within the network (MacArthur and Wilson 1967; Levins 1970; Smith et al. 2012). However, movements of individuals throughout the network are dependent on the proximity of ponded wetlands to others. Decreased inundation probabilities or the complete loss of individual wetlands could have severe implications for plant and animal populations, because they restrict the dispersal of individuals in response to changing environmental conditions, and thereby reduce the persistence of metapopulations and ability of species to adjust their ranges (Hanski and Gilpin 1991; Clergeau and Burel 1997; Opdam and Wascher 2004; Becker et al. 2007; Jetz et al. 2007; Smith et al. 2012).

Since European settlement, many playas in the Great Plains have been lost due to drainage, deliberate filling, the excavation of ditches and pits, land-use change, watershed alterations, and increased sedimentation rates (Samson and Knopf 1994; Luo et al. 1997; Smith 2003; Johnson et al. 2012; Burris and Skagen 2013). Moreover, the persistence of remaining wetlands is threatened by increasing sediment accumulation, which could be exaggerated by regionally predicted climate change (Luo et al. 1997; Burris and Skagen 2013; Uden et al. 2015). Large-scale wetland losses have not only reduced the total available number and area of extant wetlands, and wetland density, but also reduced network connectivity by increasing the distance among remaining wetlands (Johnson et al. 2012; Burris and Skagen 2013; McIntyre and Strauss 2013; Albanese and Haukos 2017).

The Rainwater Basin region in south-central Nebraska has experienced some of the largest losses of wetlands in the Great Plains (Schildman and Hurt 1984; Bishop and Vrtiska 2008; Nugent et al. 2015; Tang et al. 2016). Spanning $\sim 15,800 \mathrm{~km}^{2}$, the Rainwater Basin region once harbored $\sim 12,000$ shallow predominantly wind-formed playa wetlands, ranging from $<1$ to 400 ha, that together formed a complex network of high-density, but spatially-isolated wetlands (Fig. 1; Frye 1950; Kuzila and Lewis 1993; LaGrange 2005; LaGrange et al. 2011). Due to anthropogenic activities, about $80-90 \%$ of the historical wetlands in the Rainwater Basin region have been lost or highly altered since European settlement (Schildman and Hurt 1984; Nugent et al. 2015; Tang et al. 2016). As a result of these wetland losses, wildlife populations in the Rainwater Basin might have become more isolated and could face increased local extinction rates. Unfortunately, how large-scale wetland losses have impacted the connectivity and structure of the Rainwater Basin network, and thereby wildlife populations, remains unknown. 
Fig. 1 Map of wetlands in the historical $(\mathrm{N}=11,755$ wetlands) and current $(\mathrm{N}=1164)$ extent of the Rainwater Basin region of Southcentral Nebraska

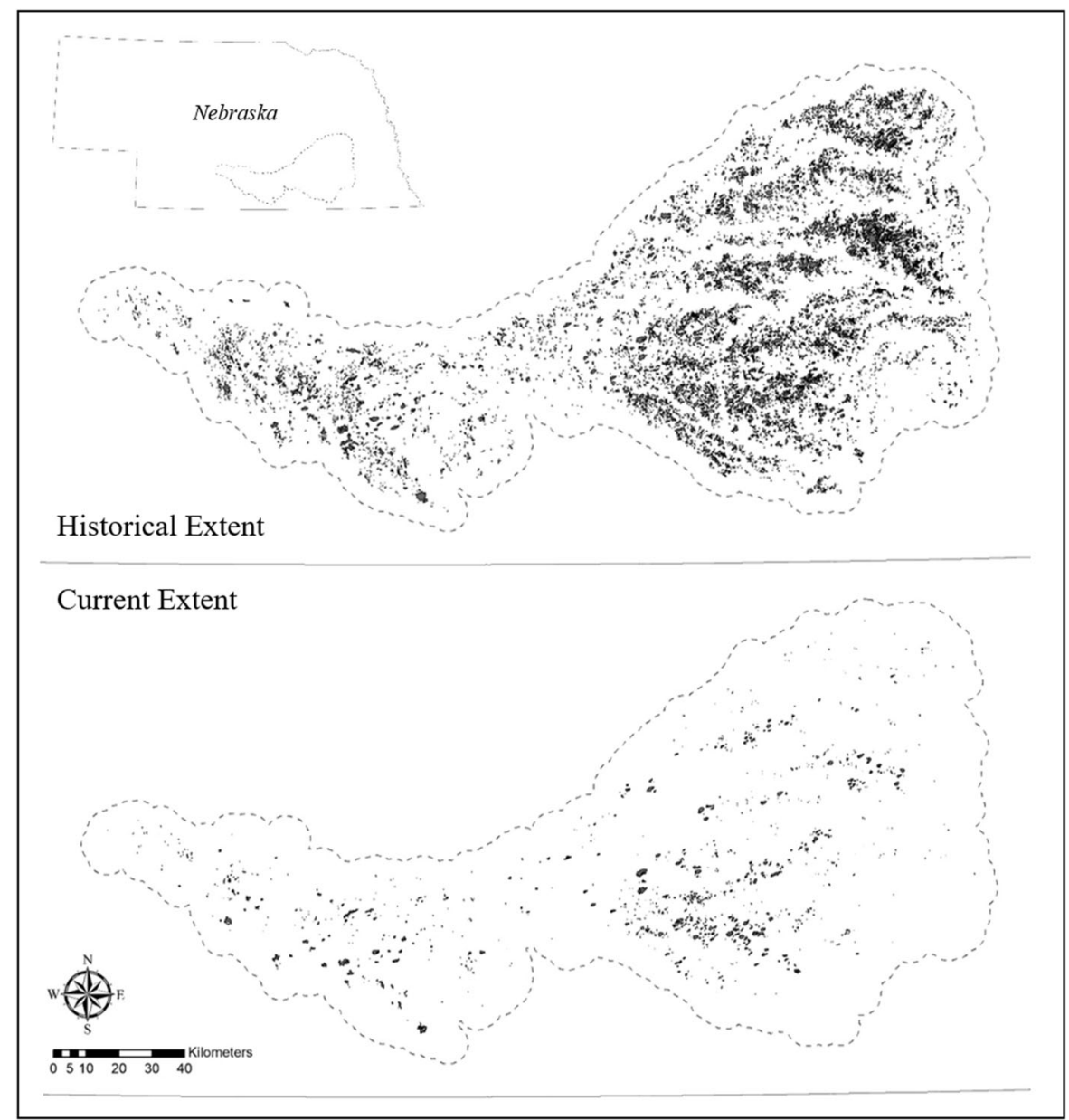

One way to assess changes in network connectivity and structure is the use of network models (Barrat et al. 2008). Network models can be used to calculate a large set of network metrics to assess different aspects of flow and connectivity of wildlife populations across spatially-structured habitat networks, such as the Rainwater Basin wetlands, and have been increasingly used in recent years (Bunn et al. 2000; Urban and Keitt 2001; Fortuna et al. 2006; Galpern et al. 2011; Rayfield et al. 2011; Foltête et al. 2012; Albanese and Haukos 2017). Network models are well suited to account for the hierarchical structure of most complex networks (Vicsek 2002; Palla et al. 2005; Clauset et al. 2008). Complex networks regularly contain wellconnected sub networks, and at lower hierarchical levels, some individual wetlands play key roles in regulating flow among sub networks, while others do not. The structure and connectivity of the network further depends on the dispersal capabilities of the wildlife species or taxa of interest (Urban et al. 2009; Albanese and Haukos 2017). Wetlands that are within flying distance for birds might be out of reach for a salamander. Because the distribution of wildlife populations and movements of individuals are directly affected by the hierarchical structure of the network, effects of wetland losses on the network need to be assessed on multiple structural levels and for a range of dispersal capabilities (Urban et al. 2009; Galpern et al. 2011; Rayfield et al. 2011; Albanese and Haukos 2017). Here, we use network models to compare the pre-European settlement and current extent of the Rainwater Basin network to assess effects of the largescale physical loss of wetlands on network connectivity and structure at the whole network and individual element level for a range of maximum dispersal distances. 


\section{Methods}

Data acquisition and manipulation

We used ArcMap 10.3.1 to assemble and examine the historical (pre-European settlement) and current extent of wetlands for the Rainwater Basin region (ESRI 2015). For the historical network, we used the Rainwater Basin Priority Wetland data layer from the Rainwater Basin Joint Venture (ScienceBase-Catalog 2013). The Priority Wetland layer was based on four sources: historical soil surveys, National Wetland Inventory (NWI) data, Soil Survey Geographic Database (SSURGO), and a 2005 Ducks Unlimited, Inc. satellite survey. The final historical layer contained a total of 11,755 wetlands in the Rainwater Basin.

To assess the current extent of the Rainwater Basin wetlands, we used 2008 NWI data from the U.S. Fish and Wildlife Service (https://www.fws.gov/wetlands/ data/Mapper.html). Here, we focused on palustrine emergent wetlands (NWI code: PEM1) within the historical extent of the Rainwater Basin, and eliminated man-made pits, ditches, and reservoirs. Although irrigation pits and ditches might be used by some species, such as frogs (Uden et al. 2014), they generally have limited utility as wetland habitat for most native wildlife. We limited our analyses of the current network to wetlands that fell within or were adjacent to polygons representing historical wetlands, which excluded a small number of wetlands with different soil characteristics to enable a direct comparison of both networks. The NWI dataset contained some wetlands where portions were classified differently than palustrine emergent, and wetlands that were dissected by roads. As a result, some wetlands were comprised of multiple adjacent or nearby $(<25 \mathrm{~m})$ polygons that were labeled as palustrine emergent. Following visual inspection of these conditions, we merged adjacent or nearby polygons to represent a single wetland. In some cases $(<20)$, historical wetlands were represented in the current extent by several smaller wetlands that were $\geq 100 \mathrm{~m}$ apart. We considered those smaller wetlands as separate wetlands for the purpose of our analysis of the current wetland network. Our actions resulted in the inclusion of 1164 wetlands in the current Rainwater Basin network.

For our analyses of the historic and current extent of the Rainwater Basin, we focused on the physical presence of wetlands alone and decided not to include the more dynamic nature of the ecological state of wetlands in the network in these analyses (e.g., probability of inundation, hydroperiod; Barrat et al. 2008; Urban et al. 2009; Galpern et al. 2011; Albanese and Haukos 2017). Analyses based on the physical location of wetlands are well-suited to explore main patterns in network connectivity and structure, as well as to assess loss of network potential (Urban et al. 2009; Albanese and Haukos 2017).

\section{Calculating network metrics}

We used Program Pajek to calculate network metrics and compare network structure and connectivity between the historical and current extent of the Rainwater Basin wetlands (Mrvar and Batagelj 2016; Albanese and Haukos 2017). First, we imported network data for both networks by using the centroid location of each wetland as a node. We then constructed a series of networks by gradually increasing the maximum dispersal distance (h) by $500-\mathrm{m}$ intervals until all wetlands within the network were connected to at least one other wetland $(\mathrm{h}=0.5-12.0 \mathrm{~km})$. Along a continuum of link lengths, or maximum dispersal distances, there will be ranges of link lengths where patterns in connectivity and structure in the network will remain relatively constant, while at other lengths rapid changes in the network can be observed (Barrat et al. 2008; Albanese and Haukos 2017). Therefore, key similarities and differences among wildlife taxa in response to largescale losses of wetlands can be explored. Although the flow among nodes can be modeled in more complex ways with the use of kernel density estimators or distance-decay functions, we used a binary presence or absence of flow among nodes based on absolute distance alone. A binary presence or absence of flow still implies that movements are more frequent among proximal wetlands than among wetlands that are further removed from each other (Bunn et al. 2000; Urban et al. 2009; Albanese and Haukos 2017). For both the historical and current network, and for each 500-m step in maximum dispersal distance, we calculated a set of network metrics on two structural levels: the whole network and individual elements, or wetlands (Rayfield et al. 2011; Albanese and Haukos 2017). 
At the whole network level, we calculated the maximum cluster size and network diameter, two commonly used metrics of landscape connectivity (Bunn et al. 2000; Urban and Keitt 2001; Urban et al. 2009; Albanese and Haukos 2017). Maximum cluster size is defined as the total number of wetlands in the largest connected subnetwork. Rapid declines in maximum cluster size indicate values of dispersal distance at which the network breaks into smaller disconnected subnetworks and no longer functions as one global network (Barrat et al. 2008; De Nooy et al. 2011). The network diameter is measured as the number of links in the longest most direct path between any pair of wetlands in the network, and quantifies how dispersal distance affected the directness, or efficiency, of flow throughout the network (Barrat et al. 2008; De Nooy et al. 2011). The diameter of the network often increases when decreasing the maximum dispersal distance, as longer direct links are eliminated and the longest shortest path requires more indirect links to reach its destination.

At the element level, we calculated the degree centrality and betweenness centrality for each wetland to assess their relative importance to network connectivity. The degree centrality, or degree, is the total number of direct links that a wetland has with other wetlands in the network (Barrat et al. 2008; De Nooy et al. 2011). Well-connected wetlands with high degree could reduce extinction risk of local populations by allowing flow from many neighboring wetlands (Urban et al. 2009). The betweenness centrality measures which fraction of the total number of shortest, most direct, paths between any pair of wetlands in the network pass through the wetland of interest (Barrat et al. 2008; De Nooy et al. 2011). Wetlands with high betweenness scores are important for flow within a network and could regulate flow among subnetworks. Betweenness can therefore be used to assess which wetlands function as "stepping stones" in the network (Urban et al. 2009). Wetlands with high degree and high betweenness values could therefore be especially important for conservation (Albanese and Haukos 2017). We constructed visual depictions of network metrics with ArcGIS and base functions of R (ESRI 2015; R Core Team 2017).

\section{Results}

We found that the number of wetlands in the Rainwater Basin has decreased by $90 \%$ between the historical and current extents (11,755 vs. 1164 wetlands). The large-scale loss of wetlands increased the average distance to the nearest neighboring wetland by $\sim 150 \%$ from $486 \pm 3 \mathrm{SE} \mathrm{m}$ for the historical network to $1233 \pm 38 \mathrm{~m}$ for the current network. Many wetlands $\leq 20$ ha were either lost from the network or decreased in size, while wetlands $>20$ ha were lost at relatively lower levels, which has resulted in a $63 \%$ increase in average wetland size from $6.98 \pm 0.19 \mathrm{SE}$ ha for the historical extent to $11.35 \pm 0.88$ ha for the current extent (Fig. 2).

\section{Whole network metrics}

Wetland losses had substantial consequences for network connectivity. The average degree per wetland was consistently lower for the current extent, and decreased by $84 \%$ at a $12-\mathrm{km}$ dispersal distance $(395.3 \pm 1.5 \mathrm{SE}$ vs. $62.0 \pm 1.41)$ to $69 \%$ at a $500-\mathrm{m}$ dispersal distance $(1.3 \pm 0.01$ vs. $0.4 \pm 0.02$; Fig. 3$)$. Maximum wetland cluster size declined with declining dispersal distance for both the historic and current extent of the Rainwater Basin. However, the largest cluster in the historical network remained close to $100 \%$ of the network until a dispersal distance of

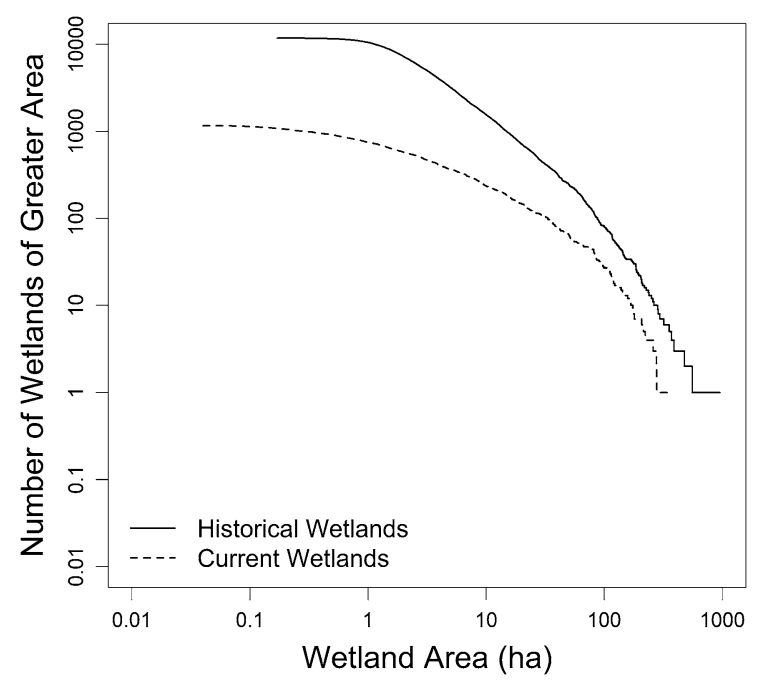

Fig. 2 Cumulative size distribution of wetlands for the current and historical extent of wetlands in the Rainwater Basin region of south-central Nebraska 


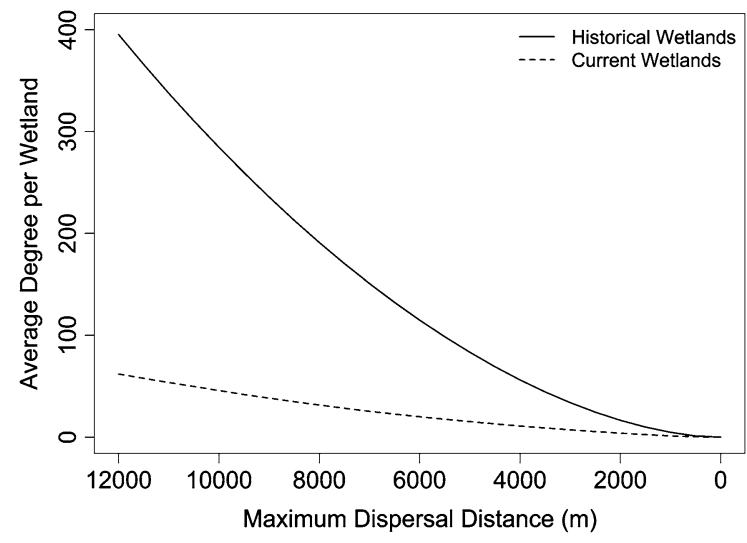

Fig. 3 Average degree (number of links per wetland) as a function of maximum dispersal distance for the current and historical extent of wetlands in the Rainwater Basin region of south-central Nebraska

$3.0 \mathrm{~km}$ was reached, while the size of the largest cluster in the current network decreased rapidly at a dispersal distance of $9.5 \mathrm{~km}$ (Fig. 4a). Both networks separated into similarly geographically located clusters as a result of restrictions in dispersal distances. First, networks split into a western and larger eastern half at $3.0 \mathrm{~km}$ for the historical network and $9.5 \mathrm{~km}$ for the current network (Fig. 5). At $5.5 \mathrm{~km}$, the eastern half of the current network split in three parts along a north-south axis, while this only happened in the historical network when maximum dispersal had been decreased to $2.0 \mathrm{~km}$. Finally, the current network is split in many smaller clusters at $2.0 \mathrm{~km}$, while the same happens at a dispersal distance of $1.0 \mathrm{~km}$ in the historical network (Fig. 5).

Patterns in network diameter closely followed changes in maximum cluster size in both the historical and current networks (Fig. 4b, c). Ranges of decreasing maximum dispersal distances that led to large breaks in the network logically coincided with sharp decreases in network diameter. In contrast, for ranges of decreasing maximum dispersal distance where cluster size remained relatively similar, network diameter kept increasing until the last remaining links among clusters were broken, indicating a lowered efficiency of movements before large breaks in the network. Furthermore, the diameter of the current network at $12 \mathrm{~km}$ is $\sim 22 \%$ larger than the historical extent, which indicates a decrease in the efficiency of movements even when the entire network is connected.
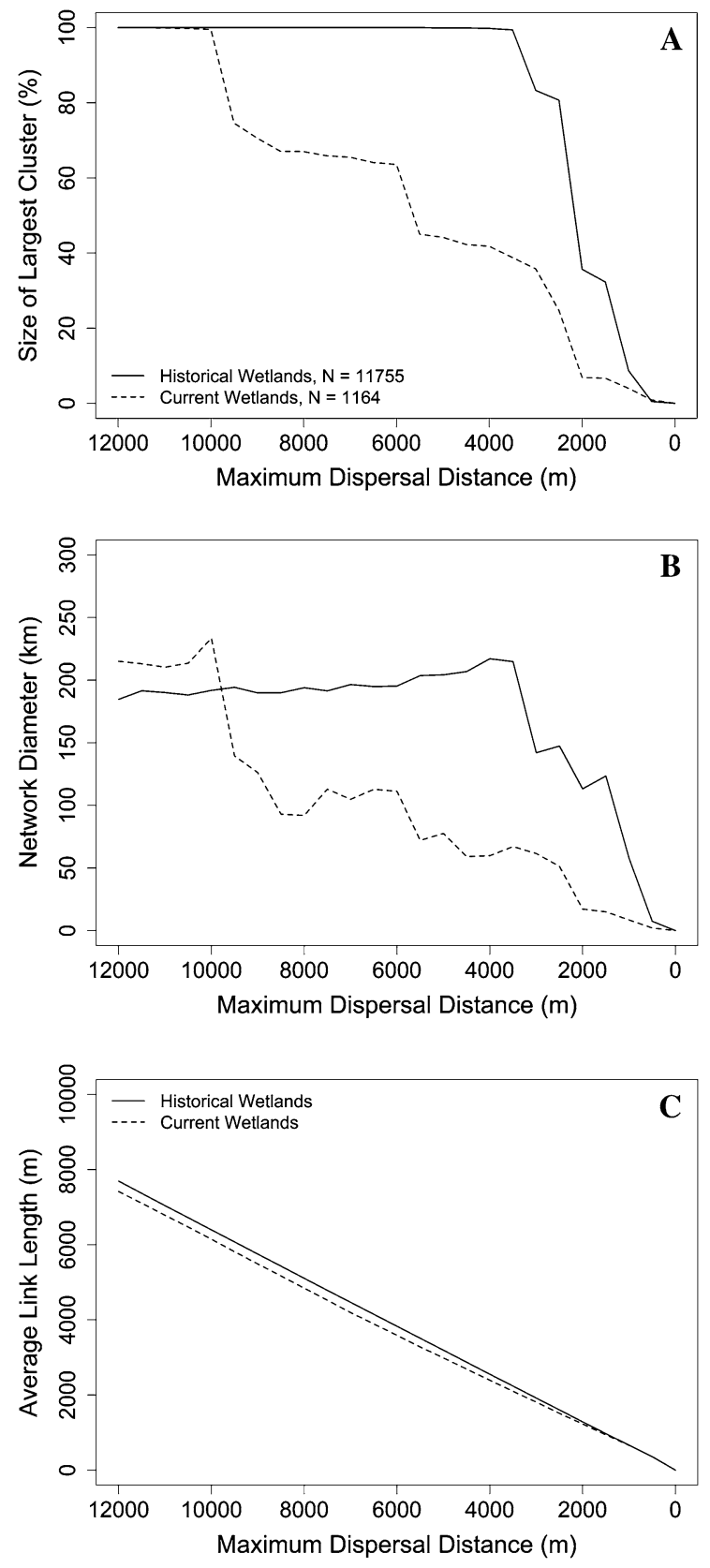

Fig. 4 Relative size of the largest remaining cluster in the network (a) and network diameter (b) as a function of maximum dispersal distance for the current and historical extent of wetlands in the Rainwater Basin region of south-central Nebraska. Network diameter is defined as the number of links in the shortest longest path multiplied by the average link length at each maximum dispersal distance (c) 

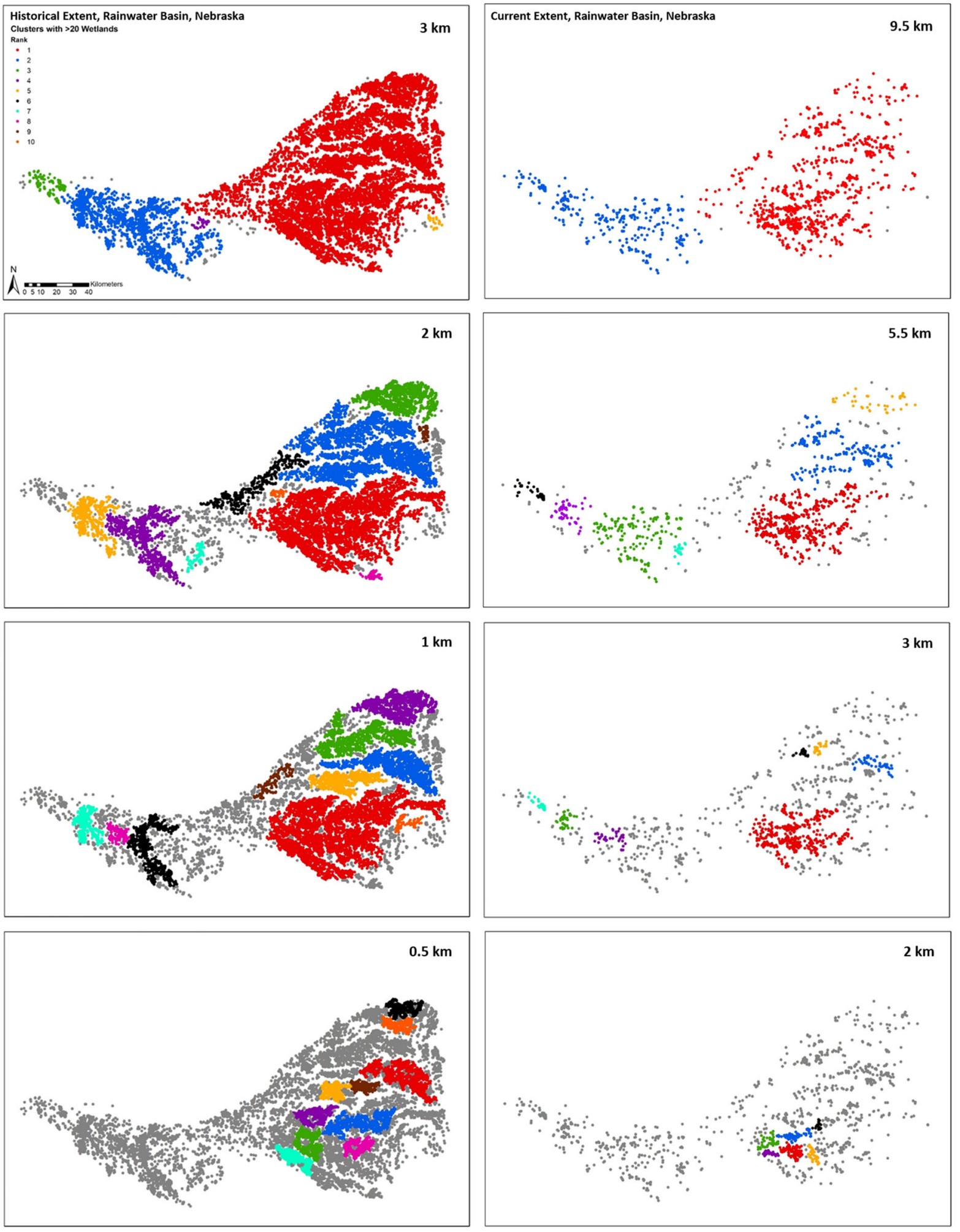
4Fig. 5 The ten largest clusters with at least 20 wetlands for four dispersal distances $(3.0,2.0,1.5$, and $1.0 \mathrm{~km})$ for the historical extent (left panels) and four dispersal distances (9.5, 5.5, 3.0, and $2.0 \mathrm{~km}$ ) for the current extent (right panels) of wetlands in the Rainwater Basin region of south-central Nebraska. Depicted dispersal distances coincide with significant drops in maximum network cluster size (see Fig. 4a)

\section{Individual wetlands}

We found that patterns in degree centrality differed between historical and current networks. At dispersal distances $\geq 2 \mathrm{~km}$, the historical network contained multiple concentrations of wetlands with high degree centrality, almost all located in the eastern half of the network (Fig. 6). In the current network, wetlands with the highest degree were all concentrated in the southwest of the eastern half of the network (Fig. 6). Wetlands with high degree centrality became less clustered and more evenly distributed throughout the
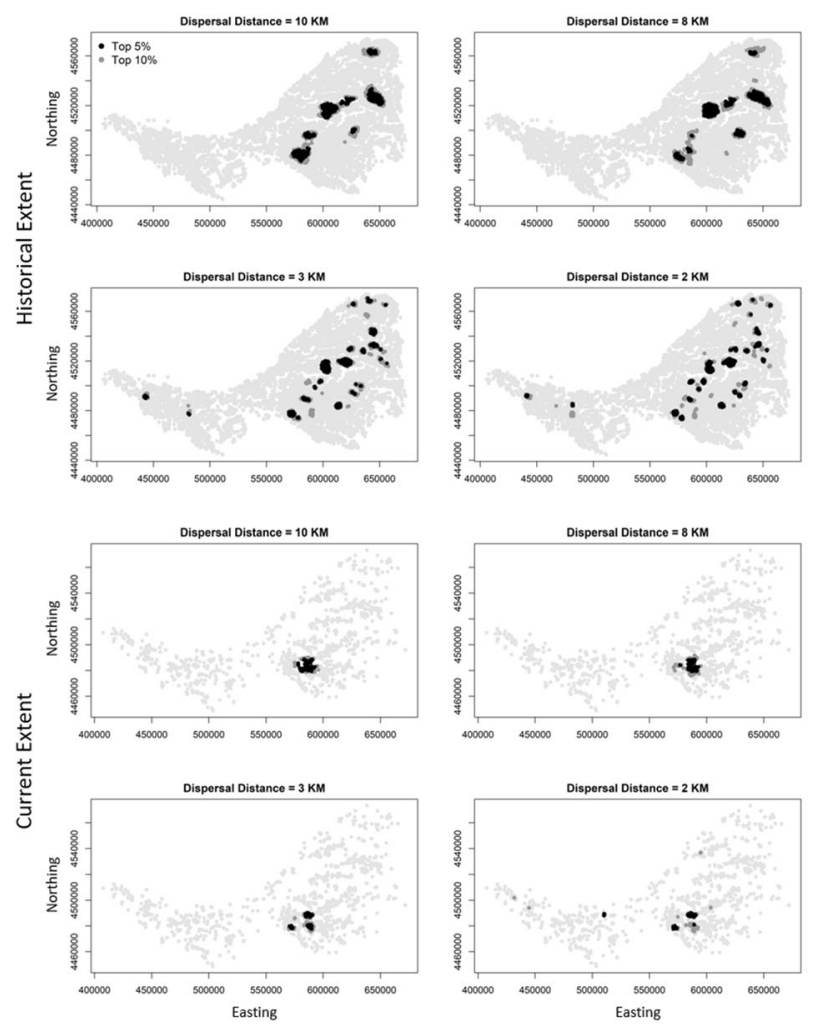

Fig. 6 The degree centrality as a function of maximum dispersal distance for the historical (top 8 panels) and current extent (bottom 8 panels) of wetlands in the Rainwater Basin region of south-central Nebraska. Wetlands with a top $5 \%$
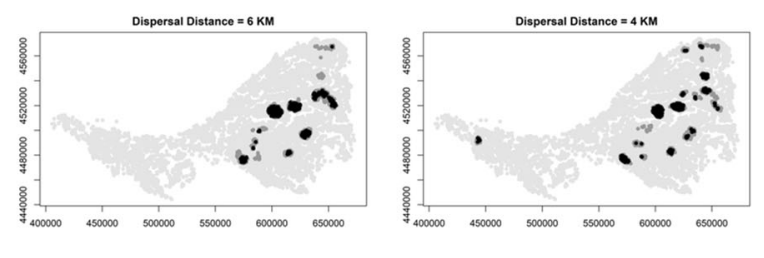

By directly comparing network metrics on multiple structural levels, we showed that large-scale wetland losses in the Rainwater Basin have substantially
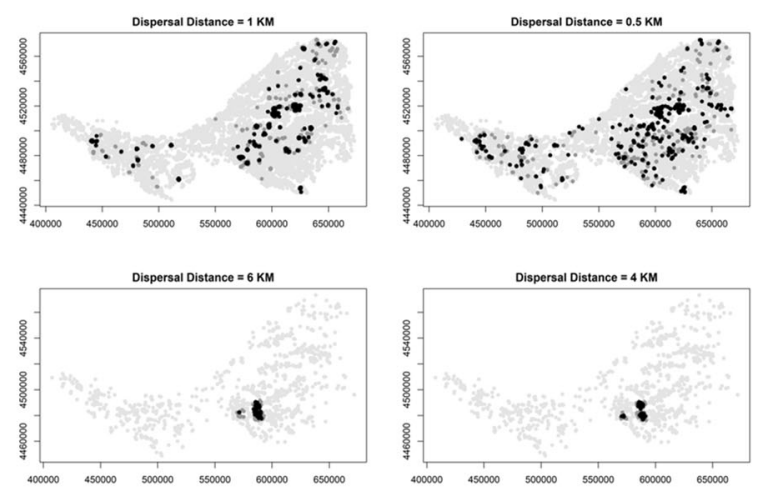

network at lower maximum dispersal distances ( $\mathrm{h}<2 \mathrm{~km}$ ) for both the historical and current extent.

Which wetlands have the greatest betweenness centrality values was dependent on the maximum dispersal distance. Before the network decomposed into multiple large clusters, wetlands with the highest betweenness centrality scores were mostly located along an east to west axis where they connected two relatively large clusters. After the western and eastern halves of the network had split, wetlands with the part of the network, where they connected the northern half to the south (Fig. 7).

\section{Discussion}
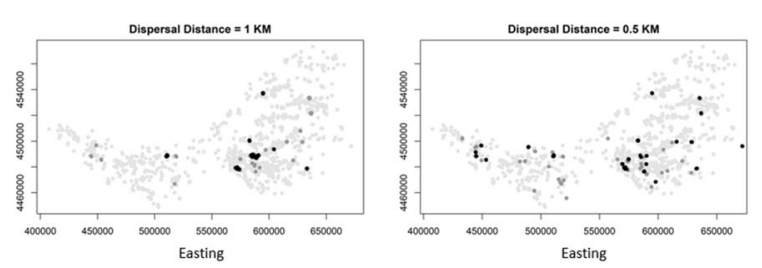

degree centrality score are depicted in black, wetlands with a top $10 \%$ score in dark gray, and wetlands with a lower score in light gray 

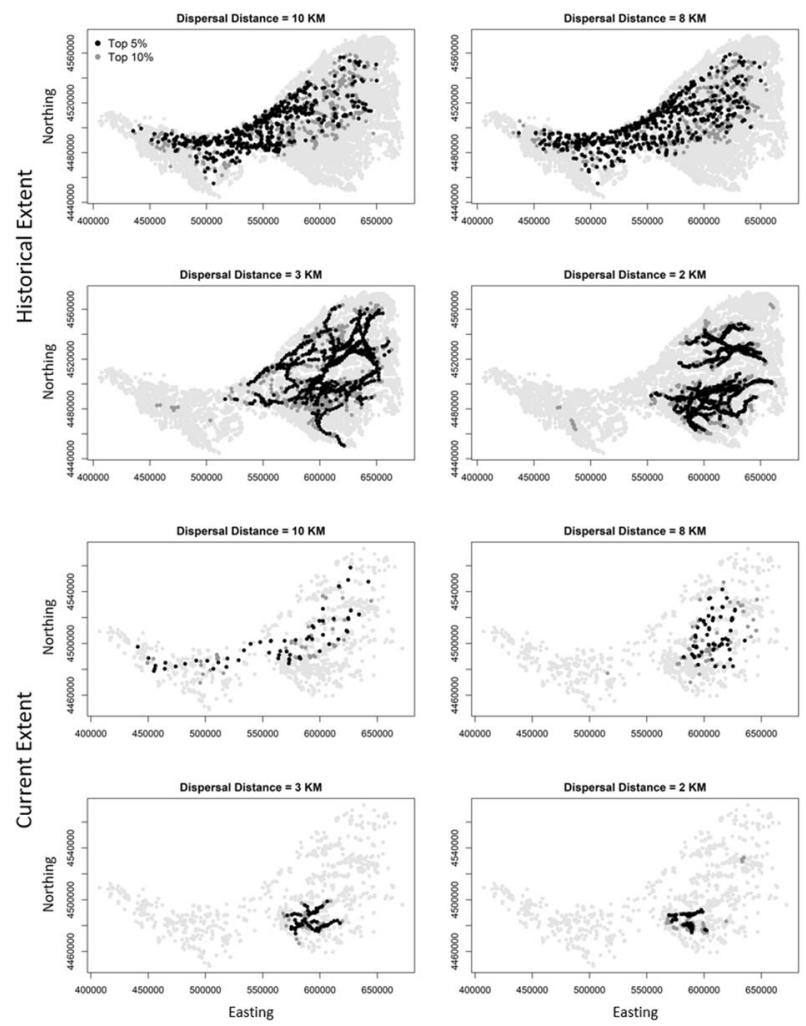

Fig. 7 The betweenness centrality as a function of maximum dispersal distance for the historical (top 8 panels) and current extent (bottom 8 panels) of wetland in the Rainwater Basin region of south-central Nebraska. Wetlands with a top 5\%

altered network structure and reduced network connectivity. Losses of playa wetlands in the Rainwater Basin have been relatively evenly spread throughout the network, but resulted in a $\sim 150 \%$ increase in the distance to the nearest wetland. In general, greater distances among wetlands have likely made it harder for individuals of species with limited movement capabilities to disperse throughout the Rainwater Basin, which will increase local extinction risk of wildlife populations and reduce persistence of metapopulations (Hanski and Gilpin 1991; Clergeau and Burel 1997; Opdam and Wascher 2004; Becker et al. 2007; Jetz et al. 2007; Smith et al. 2012).

\section{Effects of maximum dispersal distance on network connectivity}

Effects of wetland losses on the connectivity and structure of the Rainwater Basin network were strongly dependent on the maximum dispersal
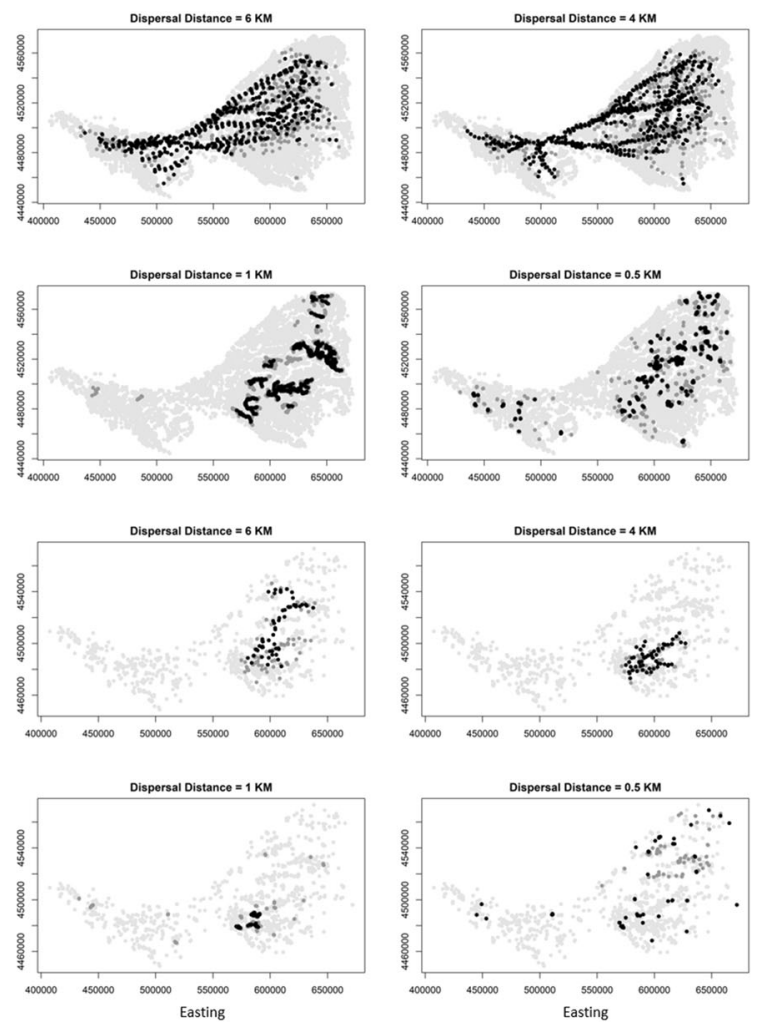

betweenness centrality score are depicted in black, wetlands with a top $10 \%$ score in dark gray, and wetlands with a lower score in light gray

distance, and are therefore species-specific. At the whole network level, we found that losses have decreased the average degree of wetlands and decreased the maximum cluster size for most tested maximum dispersal distances. Wildlife species with low dispersal capabilities $(<3.5 \mathrm{~km}$; e.g., amphibians and invertebrates) were already restricted to subnetworks in the historical network, but are now facing greater levels of isolation as previously large subnetworks have broken into smaller clusters. Populations of wildlife species with intermediate dispersal capabilities (3.5-9.5 km; e.g. turtles, resident birds, and small mammals) were fully connected by dispersal events of individuals throughout the complete historical network, but are much more restricted in the current extent. Populations of these species are now more likely to function in spatially-isolated metapopulations, instead of one large metapopulation. Last, populations of species with dispersal capabilities $>9.5 \mathrm{~km}$, such as migratory and some resident birds, 
and larger mammals, are still connected throughout the entire Rainwater Basin network, but an increase in network diameter indicates that dispersal events might be more scarce. Because the current Rainwater Basin network remains fully connected for distances $>9.5 \mathrm{~km}$, these species might be affected more by reductions in local density, total area, or quality of habitat instead (Naugle et al. 1999; Fairbairn and Dinsmore 2001). Consequences of wetland losses on network connectivity in the Rainwater Basin are greatest for plant and wildlife populations with dispersal capabilities $<3.5 \mathrm{~km}$, which might face increased local extinction risks and reduced persistence of metapopulations (Hanski and Gilpin 1991; Clergeau and Burel 1997; Opdam and Wascher 2004; Becker et al. 2007; Jetz et al. 2007; Smith et al. 2012).

The relative importance of individual wetlands to network connectivity was also strongly dependent on the maximum dispersal distance in both the historical and the current extent of the Rainwater Basin network. Which wetlands had high betweenness centrality scores, and were therefore important for regulating flow through the network as "stepping stones", shifted substantially at ranges of maximum dispersal distances at which the network broke into smaller subnetworks. Because wetland losses in the Rainwater Basin have substantially decreased the maximum dispersal distance at which these breaks occur, those wetlands in the Rainwater Basin important for local and long-distance movements of species with dispersal capabilities of $<10 \mathrm{~km}$ have changed dramatically since European settlement.

The dependence of the relative importance of individual wetlands on maximum dispersal distance poses an important problem for conservation. Most studies that have tested effects of habitat loss on network connectivity have been limited to a single maximum dispersal distance, or species (Bunn et al. 2000; Urban and Keitt 2001; Urban et al. 2009; but see Uden et al. 2014; Albanese and Haukos 2017). However, which wetlands should be prioritized for conservation likely depends on dispersal capabilities of the species or taxa of interest, with potential future losses of wetlands further influencing the relative importance of remaining wetlands to the network. To assess effects of habitat loss on a range of species, researchers would therefore benefit from the development of metrics that indicate the value of individual wetlands to network connectivity at a multitude of maximum dispersal distances. Nevertheless, by maintaining current levels of connectivity by preserving wetlands that form dense clusters at fine spatial scales, and restoring connections between subnetworks to facilitate long-range dispersal events of species with limited dispersal capabilities, conservationists might be able to preserve a broad range of biodiversity.

The role of playa characteristics on network connectivity

Although our direct comparison of network metrics across the historical and current extent of the Rainwater Basin provides useful knowledge on the connectivity and structure of the Rainwater Basin network, considering physical loss alone may be an oversimplification of this large and complex network. Playa wetlands are dynamic habitats and their contributions to the network of inundated wetlands at any given time is directly driven by their inundation probability and hydroperiod (Barrat et al. 2008; Urban et al. 2009; Galpern et al. 2011; Albanese and Haukos 2017), and, at larger spatial scales, by local wetland densities and how easy it is for species to move through the surrounding landscape. (Graf et al. 2007; McIntyre and Strauss 2013; Ruiz et al. 2014). In reality, only a subset of wetlands will be inundated in any given year, depending on the location and amounts of precipitation events, and on how much individual wetlands or entire watersheds have been altered by humans (Johnson et al. 2011). In most years only a subset of wetlands are inundated; therefore, populations of wildlife species with limited dispersal capability (e.g. most amphibians such as tiger salamanders, toads; plants; and aquatic invertebrates) will effectively be subdivided in spatially-isolated subpopulations. Long-distance dispersal among these subpopulations is then only possible in wet years, when enough playa wetlands are inundated to function as "stepping stones" (Albanese and Haukos 2017).

Understanding how inundation probability of individual playas influence network connectivity would be especially important for the Rainwater Basin region. Complex real-world networks, including playa wetland systems like the Rainwater Basin, often have high levels of redundancy (Fortuna et al. 2006; Barrat et al. 2008; Albanese and Haukos 2017). In networks with high redundancy, there are many alternative pathways for individuals to travel among subpopulations in 
response to unpredictable and dynamic environmental conditions. This will increase overall connectivity of the network, especially when pathways are available in years when others are not. Unfortunately, largescale wetland losses in the Rainwater Basin have likely reduced the redundancy of the network, and long-distance dispersal among subpopulations is therefore likely more reliant on the availability of remaining wetlands and pathways in the current extent and limited to a relatively small subset of extremely wet years.

The inundation probability, and therefore the availability, of playa wetlands for many species in the Rainwater Basin will likely be affected by future climate change. Predicted increases in temperature and decreasing precipitation events, albeit at greater intensities, in the Great Plains will likely reduce the long-term inundation probability of playa wetlands; thereby further reducing the availability of pathways for long-distance dispersal at decadal or longer temporal scales (Burris and Skagen 2013; IPCC 2014; Albanese and Haukos 2017). Reduced redundancy of pathways among wetlands within the Rainwater Basin has likely increased the time between years with sufficient precipitation for long-distance dispersal, and it is likely that climate change will exacerbate this issue. Species with limited dispersal capabilities, like the tiger salamander and native toads that are largely limited to dispersal $<2 \mathrm{~km}$ (Orloff 2011), have already seen severe reductions in network connectivity in the Rainwater Basin, with the largest cluster size decreasing from 4191 to 80 wetlands in the current extent. Low inundation probabilities of wetlands during dry years in combination with low redundancy in the network due to past wetland losses could sharply increase the risk of local extinction of populations of tiger salamanders and species with similar dispersal capacity. Understanding the influence of inundation probability and other characteristics of playa wetlands on the connectivity of the Rainwater Basin network, especially in the light of past losses and future climate change is therefore essential. Our results based solely on the geographical location of wetlands reflect the effect of physical wetland loss on the network potential of the Rainwater Basin. Consideration of both physical and functional loss would likely result in a network that is more fragmented in reality (Albanese and Haukos 2017). However, to what extent wetland characteristics like inundation probability play a role in network connectivity of the Rainwater Basin remains unclear.

\section{Implications for conservation}

Our analyses have shown that large-scale wetland losses since European settlement have substantially decreased connectivity and altered the structure of the Rainwater Basin wetland network. Assessing effects of past wetland losses can also provide important insights for conservation. Where habitat patches remain in the landscape and how characteristics of remaining patches have changed over time could illuminate causes of past losses. Most playa wetlands that were lost from the Rainwater Basin were relatively small $(\leq 20$ ha), likely because smaller wetlands were preferentially drained and leveled due to their size and increased sediment accumulation rates in the region has disproportionally affected smaller wetlands (Luo et al. 1997; Burris and Skagen 2013). Sediment accumulation rates will likely continue to increase because of locally predicted increases in summer temperature, intensity of precipitation events, and continued conversion of perennial vegetation cover to row crops. Although conservation measures, such as restrictions on tilling, could offset some of these losses, it is likely that remaining small wetlands face an even greater risk of disappearing from the landscape in the future (Luo et al. 1997; Burris and Skagen 2013).

Future wetland losses will likely continue to decrease network connectivity in the Rainwater Basin, thereby further fragmenting wildlife populations with steadily increasing dispersal capabilities. However, the relative effect of loss of individual wetlands on decreasing network connectivity depends on their relative importance, which is based on physical location and functionality. Wetlands with high degree or betweenness centrality perform key functions as hubs or stepping stones in the network, and the loss of these key wetlands could lead to large reductions in network connectivity (Urban and Keitt 2001; Albanese and Haukos 2017). With the use of targeted removal analyses similar to Albanese and Haukos (2017) for playa networks on the Southern High Plains, we could assess the importance of key wetlands in the Rainwater Basin by comparing the effects of removing a set of key wetlands on network 
connectivity and the removal of a random subset of wetlands. However, with $>90 \%$ of wetlands already lost to the Rainwater Basin, wildlife might be highly susceptible to the future loss of any wetland because populations are already constrained by past reductions in network connectivity.

Analysis of past losses of wetlands can also help guide restoration efforts. Although most work on the effects of large-scale habitat losses on network connectivity and structure have focused on modeling future losses (Bunn et al. 2000; Urban and Keitt 2001; Schick and Lindley 2007; Albanese and Haukos 2017), network models can also be used to identify which lost wetlands would most improve network connectivity when restored to the network. Furthermore, information on the relative importance of wetlands to network connectivity can be combined with prioritization models based on habitat quality, such as the Rainwater Basin Easement Priority Model created by the Rainwater Basin Joint Venture (ScienceBase-Catalog 2013). Network models can therefore be a useful tool to aid land managers in selecting wetlands that perform important roles in the network for both conservation and restoration.

Acknowledgements This study was funded by U.S. Fish and Wildlife Service, Great Plains Landscape Conservation Cooperative research and National Science Foundation Macrosystems (1544083) grants administered through the U.S. Geological Survey Fort Collins Science Center and Kansas Cooperative Fish and Wildlife Research Unit. We are grateful for additional support provided by Gene Albanese, Chris Wright, and the Division of Biology at Kansas State University. We thank J.S. Lamb, L.E. Rosen, B.E. Ross, E.L. Weiser, and two anonymous reviewers for helpful suggestions and feedback on previous versions of the manuscript. The use of trade names or products does not constitute an endorsement by the United States Government, the United States Department of Interior, or other sponsoring or participating agencies.

\section{References}

Albanese G, Haukos DA (2017) A network model framework for prioritizing wetland conservation in the Great Plains. Landscape Ecol 32:115-130

Barrat A, Barthélemy M, Vespignani A (2008) Dynamical processes on complex networks. Cambridge University Press, Cambridge

Becker CG, Fonseca CR, Haddad CFB, Batista RF, Prado PI (2007) Habitat split and the global decline of amphibians. Science 318:1775-1777

Bishop AA, Vrtiska M (2008) Effects of the Wetland Reserve Program on waterfowl carrying capacity in the Rainwater
Basin region of south-central Nebraska. A conservation effects assessment project, wildlife component assessment. USDA NRCS Publication, U.S. Fish and Wildlife Service, Grand Island, NE

Bunn AG, Urban DL, Keitt TH (2000) Landscape connectivity: a conservation application of graph theory. J Environ Manag 59:265-278

Burris L, Skagen SK (2013) Modeling sediment accumulation in North American playa wetlands in response to climate change. Clim Change 117:69-83

Clauset A, Moore C, Newman MEJ (2008) Hierarchical structure and the prediction of missing links in networks. Nature 453:98-101

Clergeau P, Burel F (1997) The role of spatio-temporal patch connectivity at the landscape level: an example in a bird distribution. Landsc Urban Plan 38:37-43

De Nooy W, Mrvar A, Batagelj V (2011) Exploratory social network analysis with Pajek, 2nd edn. Cambridge University Press, New York

ESRI (2015) ArcMap 10.3.1. Environmental Systems Research Institute, Redlands, CA

Fairbairn SE, Dinsmore JJ (2001) Local and landscape-level influences on wetland bird communities of the prairie pothole region of Iowa, USA. Wetlands 21:41-47

Foltête J, Clauzel C, Vuidel G, Tournant P (2012) Integrating graph-based connectivity metrics into species distribution models. Landscape Ecol 27:557-569

Fortuna MA, Gomez-Rodriguez C, Bascompte J (2006) Spatial network structure and amphibian persistence in a stochastic environment. Proc R Soc Lond B 273:1429-1434

Frye JC (1950) Origin of Kansas Great Plains depressions. State Geol Surv Kansas Bull 86:1-20

Galpern P, Manseau M, Fall A (2011) Patch-based graphs of landscape connectivity: a guide to construction, analysis and application for conservation. Biol Conserv 144:44-55

Graf RF, Kramer-Schadt S, Fenandez N, Grimm V (2007) What you see is where you go? Modeling dispersal in mountainous landscapes. Landscape Ecol 22:853-866

Hanski I, Gilpin M (1991) Metapopulation dynamics: brief history and conceptual domain. Biol J Linn Soc 42:3-16

Haukos DA, Smith LM (1993) Moist soil management of playa lakes for migrating and wintering ducks. Wildl Soc Bull 21:288-298

Haukos DA, Smith LM (1994) The importance of playa wetlands to biodiversity of the southern high plains. Landsc Urban Plan 28:83-98

Intergovernmental Panel on Climate Change (IPCC) (2014) Climate change 2014: impacts, adaptation, and vulnerability. Cambridge University Press, Cambridge

Jetz W, Wilcove DS, Dobson AP (2007) Projected impacts of climate and land-use change on the global diversity of birds. PLoS Biol 5:1211-1219

Johnson LA, Haukos DA, Smith LM, McMurry ST (2012) Physical loss and modification of Southern Great Plains playas. J Environ Manag 112:275-283

Johnson WP, Rice MB, Haukos DA, Thorpe PP (2011) Factors influencing the occurrence of inundated playa wetlands during winter on the Texas High Plains. Wetlands 31:1287-1296 
Kuzila MS, Lewis DT (1993) Soils in rain basins of south central Nebraska, properties, genesis and classification. Soil Sci Soc Am J 37:155-161

LaGrange TG (2005) Guide to Nebraska's wetlands and their conservation needs, 2nd edn. Nebraska Game and Parks Commission, Lincoln, NE

LaGrange TG, Stutheit R, Gilbert M, Shurtliff D, Whited PM (2011) Sedimentation of Nebraska's playa wetlands: a review of current knowledge and issues. Nebraska Game and Parks Commission, Lincoln, NE

Levins R (1970) Extinction. In: Gerstenhaber M (ed) Lectures on mathematics in the life sciences. American Mathematical Society, Providence, pp 77-107

Luo H, Smith LM, Allen BL, Haukos DA (1997) Effects of sedimentation on playa wetland volume. Ecol Appl 7:247-252

MacArthur RH, Wilson EO (1967) The theory of island biogeography. Princeton University Press, Princeton, NJ

McIntyre NE, Strauss RA (2013) A new, multi-scaled graph visualization approach: an example within the playa wetland network of the Great Plains. Landscape Ecol 28:769-782

Mrvar A, Batagelj V (2016) Analysis and visualization of large networks with program package Pajek. Complex Adapt Syst Model 4:6

Naugle DE, Higgins KF, Nusser SM, Johnson WC (1999) Scaledependent habitat use in three species of prairie wetland birds. Landscape Ecol 14:267-276

Nugent E, Bishop A, Grosse R, LaGrange T, Varner D, Vrtiska M (2015) An assessment of landscape carrying capacity for waterfowl and shorebirds in Nebraska's Rainwater Basin. A conservation effects assessment project wildlife component assessment report. Rainwater Basin Joint Venture, Wood River, NE

Opdam P, Wascher D (2004) Climate change meets habitat fragmentation: linking landscape and biogeographical scale levels in research and conservation. Biol Conserv 117:285-297

Orloff SG (2011) Movement patterns and migration distances in an upland population of California tiger salamander ( $\mathrm{Am}$ bystoma californiense). Herp Conserv Biol 6:266-276

Osterkamp WR, Wood WW (1987) Playa-lake basins on the Southern High Plains of Texas and New Mexico: part I. Hydrologic, geomorphic, and geologic evidence for their development. Geol Soc Am Bull 99:215-223

Palla G, Der'enyi I, Farkas I, Vicsek T (2005) Uncovering the overlapping community structure of complex networks in nature and society. Nature 435:814-818
R Development Core Team (2017) R: a language and environment for statistical computing. R Foundation for Statistical Computing, Vienna

Rainwater Basin Joint Venture (2013) The Rainwater Basin Joint Venture implementation plan. Rainwater Basin Joint Venture, Grand Island, NE

Rayfield B, Fortin M, Fall A (2011) Connectivity for conservation: a framework to classify network measures. Ecology 92:847-858

Ruiz LJ, Parikh NN, Heintzman LJ, Collins SD, Starr SM, Wright CK, Henebry GM, van Gestel N, McIntyre NE (2014) Dynamic connectivity of temporary wetlands in the Southern Great Plains. Landscape Ecol 29:507-516

Samson F, Knopf F (1994) Prairie conservation in North America. Bioscience 44:418-421

Schick RS, Lindley ST (2007) Directed connectivity among fish populations in a riverine network. $\mathrm{J}$ Appl Ecol 44:1116-1126

Schildman G, Hurt J (1984) Update of Rainwater Basin wetland survey. Survey of habitat work plan K-83, W-15-R-40. Nebraska Game and Parks Commission, Lincoln, NE

Smith LM (2003) Playas of the Great Plains. University of Texas Press, Austin, TX

Smith LM, Haukos DA, McMurry ST (2012) High plains playas. In: Batzer D, Baldwin A (eds) Wetland habitats of North America: ecology and conservation concerns. University of California Press, Berkeley, CA, pp 299-311

Smith LM, Haukos DA, McMurry ST, LaGrange T, Willis D (2011) Ecosystem services provided by playas in the high plains: potential influences of USDA conservation programs. Ecol Appl 21:S82-S92

Tang Z, Li Y, Gu Y, Jiang W, Xue Y, Hu Q, LaGrange T, Bishop A, Drahota J, Li R (2016) Assessing Nebraska playa wetland inundation status during 1985-2015 using Landsat data and Google Earth Engine. Environ Monit Assess 188:654

Uden DR, Allen CR, Bishop AA, Grosse R, Jorgensen CF, LaGrange TG, Stutheit G, Vrtiska MP (2015) Predictions of future ephemeral springtime waterbird stopover habitat availability under global change. Ecosphere 6:215.

Uden DR, Hellman ML, Angeler DG, Allen CR (2014) The role of reserves and anthropogenic habitats for functional connectivity and resilience of ephemeral wetlands. Ecol Appl 24:1569-1582

Urban DL, Keitt TH (2001) Landscape connectivity: a graphtheoretic perspective. Ecology 82:1205-1218

Urban DL, Minor ES, Treml EA, Schick RS (2009) Graph models of habitat mosaics. Ecol Lett 12:260-273

Vicsek T (2002) The big picture. Nature 418:131 